\section{Guidelines for the diagnosis and management of individuals with neurofibromatosis 1}

\author{
Rosalie E Ferner, Susan M Huson, Nick Thomas, Celia Moss, \\ Harry Willshaw, D Gareth Evans, Meena Upadhyaya, \\ Richard Towers, Michael Gleeson, Christine Steiger, Amanda Kirby \\ funded by the Joint Information Systems \\ Committee. For further information, see \\ http://jmg.bmi.com/cgi/content/full/42/ \\ $2 / 97$
}

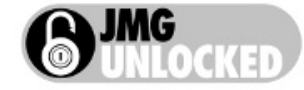

This article is available free on JMG online via the JMG Unlocked open access trial,

Neurofibromatosis 1 (NF1) is a common neurocutaneous condition with an autosomal dominant pattern of inheritance. The complications are diverse and disease expression varies, even within families. Progress in molecular biology and neuroimaging and the development of mouse models have helped to elucidate the aetiology of NFI and its clinical manifestations. Furthermore, these advances have raised the prospect of therapeutic intervention for this complex and distressing disease. Members of the United Kingdom Neurofibromatosis Association Clinical Advisory Board collaborated to produce a consensus statement on the current guidelines for diagnosis and management of NF1. The proposals are based on published clinical studies and on the pooled knowledge of experts in neurofibromatosis with experience of providing multidisciplinary clinical and molecular services for NFl patients. The consensus statement discusses the diagnostic criteria, major differential diagnoses, clinical manifestations and the present strategies for monitoring and management of NF1 complications.

See end of article for authors' affiliations

Correspondence to: Dr Rosalie E Ferner, Department of Neurology, Guy's Hospital, St Thomas' St, London SEI 9RT, UK; rosalie.ferner@kcl.ac.uk

Received 15 August 2006 Revised 14 October 2006 Accepted 16 October 2006 Published Online First 14 November 2006
D escriptions of individuals purported to have neurofibromatosis have been discovered in manuscripts dating from $1000 \mathrm{AD} .^{1}$ However, it was not until 1881 that von Recklinghausen coined the term "neurofibroma" when he observed that this benign tumour arose from the peripheral nerve sheath. ${ }^{2}$ His colleagues honoured his contribution by naming the condition von Recklinghausen's disease. However, the different forms of neurofibromatosis were not separated and delineated until the latter part of the twentieth century (tables 1, 2). The National Institutes of Health Consensus Development Conference formulated the diagnostic criteria for neurofibromatosis 1 (NFl), underlining the pivotal involvement of the skin, bone and the nervous system in the condition (table 1). ${ }^{3}$ In 1990, the NF1 gene was cloned on chromosome 17q11.2. ${ }^{45}$ Neurofibromin, the gene product, is ubiquitously expressed at high levels in the nervous system and functions as a tumour suppressor. ${ }^{6-8}$ Loss of neurofibromin through mutation leads to an increased risk of developing benign and malignant tumours in affected individuals.

\section{DIAGNOSIS OF NF 1}

NFl has a birth incidence of 1 in 2500 to 1 in 3000, the diagnosis is based on clinical assessment and two or more of the features in table 1 are required. ${ }^{3}{ }^{9}$

These diagnostic criteria are robust and have stood the test of time well. Clinicians should be aware that some individuals with mosaic/segmental NFl fulfil the diagnostic criteria as they present with six or more café au lait patches with skin-fold freckling or neurofibromas. However, the skin manifestations are in a restricted segment of the body (see section on differential diagnosis). ${ }^{10}$ Approximately half of NFl sufferers are the first in their family to have the condition. ${ }^{11}$ Children with six café au lait patches alone and no family history should be followed up as if they have the disease, as $95 \%$ of them will develop NFl. ${ }^{12}$ Occasionally, other signs of NF1 may not develop until late teens or early twenties and slit lamp examination for Lisch nodules might be helpful in these children. NF1 mutational analysis clarifies the diagnosis in some uncertain cases and in individuals contemplating prenatal diagnosis (see section on prenatal diagnosis). However, genetic testing is not advocated routinely and expert consultation is advised before it is undertaken. Furthermore, biopsy of asymptomatic cutaneous neurofibromas should not be undertaken for diagnostic purposes in individuals with clearcut NFl.

Hyperintense lesions on T2 weighted brain MRI (formerly called UBOs) are probably caused by aberrant myelination or gliosis, and are pathognomonic of NFl. ${ }^{13}$ They occur most commonly in children of 8-16 years old, tend to disappear in adulthood and have a tenuous link with cognitive impairment (see section on cognitive impairment). ${ }^{14-16}$ The presence of these lesions can assist the diagnosis of NFI but MRI under anaesthetic is not warranted for this purpose in young children. ${ }^{17}$

\section{Differential diagnosis of NF 1}

The differential diagnoses of NFl include other forms of neurofibromatosis, conditions with café au lait patches or with pigment changes confused with café au lait patches. Likewise, tumours or localised body overgrowth can be mistaken for neurofibromas (table 2). ${ }^{18-24}$

Abbreviations: MPNST, malignant peripheral nerve sheath tumours; NF1, NF2, neurofibromatosis 1, 2; OPG, optic pathway gliomas 
Table 1 Diagnostic criteria for neurofibromatosis 1 (NF1)

(NIH consensus development conference 1988)

6 or more café au lait macules $(>0.5 \mathrm{~cm}$ in children or $>1.5 \mathrm{~cm}$ in adults)

- 2 or more cutaneous/subcutaneous neurofibromas or one plexiform neurofibroma

- Axillary or groin freckling

- Optic pathway glioma

- 2 or more Lisch nodules (iris hamartomas seen on slit lamp examination)

- Bony dysplasia (sphenoid wing dysplasia, bowing of long bone \pm pseudarthrosis)

- First degree relative with NFI

It should be emphasised that one or two café au lait patches occur in $10 \%$ of the general population. Children with 3-5 café au lait patches but no other signs of NFl should be followed up in a specialist neurofibromatosis clinic as they might have mosaic NF1 or neurofibromatosis 2 (NF2). Mosaic NF1 occurs as a result of a somatic mutation in the NFI gene, the proportion of the body affected depending on the time of the mutation in embryonic development. ${ }^{10}$ The importance of making the diagnosis is that NFl complications are relatively infrequent in segmental NFI and there is a much lower risk of recurrence in offspring. Homozygotes for one of the genes causing hereditary non-polyposis cancer of the colon have café au lait patches and an affected first degree relative. However, the affected relative is a sibling and the parents are normal. ${ }^{19}$

The only subtype of NFl that is distinct and has a uniform phenotype in families is Watson syndrome. It is characterised by pulmonary stenosis, cognitive impairment, café au lait patches and few, if any, cutaneous neurofibromas. ${ }^{18}$ There is no clear evidence that neurofibromatosis-Noonan syndrome exists as a distinct phenotype with features of both syndromes. It is likely that some individuals with NFl simply have facial features akin to those of Noonan syndrome and these characteristics are not consistent within families. Molecular studies indicate that neurofibromatosis-Noonan syndrome is caused by mutations of the NFI gene, some of which have been identified in patients with classical NF.$^{20}$

NF2 is an autosomal dominant neurocutaneous disease that is clinically and genetically distinct from NFl and occurs in approximately 1 in 25000 individuals. ${ }^{21}$ It is caused by inactivating mutations on chromosome $22 \mathrm{ql} 1.2$ and is characterised by bilateral vestibular schwannomas.22 ${ }^{23}$ Affected individuals also develop schwannomas on other cranial, spinal, peripheral and cutaneous nerves. Café au lait patches are less numerous than in NFl and the skin lesions are predominantly schwannomas. Central nervous system meningiomas and gliomas are observed and slit lamp examination reveals juvenile subcapsular lens opacities in the majority of patients. ${ }^{23}$

Subcutaneous, peripheral nerve and spinal schwannomas develop in schwannomatosis without vestibular schwannomas or the ophthalmological features of NF2. ${ }^{24}$

Multiple lipomas occur primarily on the trunk, proximal thighs and distal arms, and are inherited in an autosomal dominant fashion. Biopsy is sometimes necessary to differentiate cutaneous neurofibromas from schwannomas and lipomas.

\section{ASSESSMENT AND MANAGEMENT OF CLINICAL PROBLEMS}

Once the diagnosis is considered, referral should be made to any clinician skilled in the diagnosis of NFl, including geneticists, paediatricians, neurologists or dermatologists. Routine screening investigations are not recommended for the
Table 2 Differential diagnosis of neurofibromatosis 1 $(\mathrm{NF} 1)^{10}$ 18-24

Other forms of neurofibromatosis

- Segmental/mosaic NF1

- Watson syndrome

- Autosomal dominant multiple café au lait patches alone (some allelic with NF1)

- Neurofibromatosis 2

- Schwannomatosis

Other conditions with café au lait patches

- McCune-Albright syndrome

- DNA repair syndromes

- Homozygosity for one of the genes causing hereditary non-polyposis cancer of the colon.

Conditions with pigmented macules confused with NFI

- LEOPARD syndrome

- Neurocutaneous melanosis

- Peutz-Jeghers syndrome

- Piebaldism

Localised overgrowth syndromes

- Klippel-Trenauny-Weber syndrome

- Proteus syndrome

Conditions causing tumours confused with neurofibromas

- Lipomatosis

- Banayan-Riley-Ruvalcuba syndrome

- Fibromatoses

- Multiple endocrine neoplasia type $2 \mathrm{~B}$

detection of the majority of complications associated with the condition. However, visual assessment should be performed in young children because they do not complain of visual impairment (see section on optic pathway glioma). Furthermore, given the high frequency of learning and behavioural problems in NFl children, monitoring is essential (see section on cognitive impairment). Baseline brain and spine MRI, and routine imaging of the chest and abdomen to identify asymptomatic tumours, do not influence management and should not be undertaken.

The mainstay of management is age specific monitoring of disease manifestations and patient education. At all ages it is most likely that severe disease complications such as malignant peripheral nerve sheath tumours (MPNST) will become symptomatic between appointments. NFI individuals need to be encouraged to seek review of any unusual symptoms and ask if they are related to NF1. All children with uncomplicated disease need to be assessed once a year (table 3), ideally by one paediatrician in each area to facilitate coordinated care. Older adults should be offered the opportunity of attending the clinic on an annual basis. Young adults aged 16-25 years are at a vulnerable stage of life and require education about NFl and its possible complications. Counselling about disease inheritance and psychological support are advised, particularly as neurofibromas often start to develop in late adolescence.

Monitoring after the mid-twenties depends on patient preference and disease severity. Adults with severe disease have usually been identified by this stage and require lifelong monitoring in an NFl clinic. Adults with mild disease have a much lower risk of complications. If they elect not to attend a specialist NFl clinic, they should be fully conversant with the problems that they might encounter. The minimum requirement for an asymptomatic adult is to have annual blood pressure measurement and to be aware of unusual symptoms, particularly the clinical features of malignant peripheral nerve sheath tumours and of spinal cord compression (see MPNST and neurological complications). Currently, the few specialist services for adults with NFI are run by geneticists and neurologists. Further support is available through a small network of neurofibromatosis specialist advisors developed by the Neurofibromatosis Association and part funded by the 
Table 3 Assessment of children with neurofibromatosis 1

The following should be recorded at each annual visit

- Development and progress at school

- Visual symptoms, visual acuity and fundoscopy until age 7 years (optic pathway glioma*, glaucoma)

- Head circumference (rapid increase might indicate tumour or hydrocephalus)

- Height (abnormal pubertal development)

- Weight (abnormal pubertal development)

- Pubertal development (delayed/precocious puberty due to pituitary/hypothalamic lesion)

- Blood pressure (consider renal artery stenosis, phaeochromocytoma)

- Cardiovascular examination (congenital heart disease, especially pulmonary stenosis)

- Evaluation of spine (scoliosis \pm underlying plexiform neurofibromas)

- Evaluation of the skin (cutaneous, subcutaneous and plexiform neurofibromas)

- System examination if specific symptoms

*Asymptomatic children should also have one baseline assessment of colour vision and visual fields at the appropriate developmental age.

National Health Service. The advisors have a nursing or social work background and act as patient advocates, providing support on medical, educational and emotional issues and coordinating with other professionals. An expansion of the specialist neurofibromatosis clinics and the specialist advisor network would enhance the provision of a cohesive pattern of care throughout the UK.

The manifestations of NFl are widespread and affect many of the body systems (table 4$)^{12}$

\section{The skin}

Café au lait patches and skin-fold freckling do not usually cause complications; however, some patients are distressed by the appearance of this pigmentation and may be helped by skin camouflage advice. There is no evidence to support the routine use of laser treatment for café au lait patches.

Hypopigmented macules may coexist with café au lait spots in NFl and are found in a similar distribution.

Naevus anaemicus and benign cherry angiomas (Campbell de Morgan spots) are observed more frequently in NFl than in the general population, irrespective of age. Juvenile xanthogranulomas are benign orange papules that appear transiently on the head and trunk in $1 \%$ of young children. It has been suggested that there is an increased risk of chronic myeloid leukaemia in children with NFl and xanthogranulomas. However, routine haematological testing is not warranted in this group and a recent follow-up study did not reveal any haematological malignancies in 14 children with NFl and xanthogranulomas. ${ }^{25}$

\section{Neurofibromas}

Neurofibromas are benign peripheral nerve sheath tumours that are focal cutaneous or subcutaneous, or diffuse or nodular plexiform lesions. Cutaneous neurofibromas are found in the majority of NFI individuals, usually develop in the late teens or early twenties but occasionally emerge in early childhood. ${ }^{12} 26$ Initially, some lesions have a purplish tinge and may become pedunculated as they grow. The number of neurofibromas varies between individuals and within families. ${ }^{12}{ }^{26}$ There have been no reports of these skin tumours undergoing malignant change but they often catch on clothing and cause cosmetic problems, transient stinging and itching. Irritation does not usually respond to antihistamines and the benefit of mast cell stabilisers is uncertain; excessive heat should be avoided and the use of emollients is advised.

Cutaneous neurofibromas can be removed if they cause any of the problems mentioned above. Referral to surgeons skilled in the removal of neurofibromas is advocated and plastic surgeons should be consulted for neurofibromas on the face and neck. There is no proven benefit of carbon dioxide laser treatment over surgical removal of troublesome neurofibromas but laser may be helpful for some small lesions. There is a risk of hypertrophic scarring and of recurrence of neurofibromas after removal.

Subcutaneous neurofibromas are evident on palpation of the skin, may be tender to touch and cause tingling in the distribution of the affected nerve. ${ }^{26}$ Malignant change rarely occurs and if removal is contemplated, expert advice should be

Table 4 Frequency and age of onset of major clinical manifestations of neurofibromatosis 1

\begin{tabular}{lll}
\hline Clinical manifestation & Frequency (\%) & Age of onset \\
\hline Café au lait patches & $>99$ & Birth to 12 y \\
Skin-fold freckling & 85 & 3 y to adolescence \\
Lisch nodules & $90-95$ & $>3$ y \\
Cutaneous neurofibromas & $>99$ & $>7$ y (usually late adolescence) \\
Plexiform neurofibromas & 30 (visible) -50 (on imaging) & Birth to 18 y \\
Disfiguring facial plexiform neurofibromas & $3-5$ & Birth to 5 y \\
Malignant peripheral nerve sheath tumour & $2-5$ (8-13\% lifetime risk) & $5-75$ y \\
Scoliosis & 10 & Birth to 18 y \\
Scoliosis requiring surgery & 5 & Birth to 18 y \\
Pseudarthrosis of tibia & 2 & Birth to $3 y$ \\
Renal artery stenosis & 2 & Lifelong \\
Phaeochromocytoma & 2 & $>10 y$ \\
Severe cognitive impairment (IQ $<70)$ & $4-8$ & Birth \\
Learning problems & $30-60$ & Birth \\
Epilepsy & $6-7$ & Lifelong \\
Optic pathway glioma & 15 (only 5\% symptomatic) & Birth to 7 y (up to 30 y) \\
Cerebral gliomas & $2-3$ & Lifelong \\
Sphenoid wing dysplasia & $<1$ & Congenital \\
Aqueduct stenosis & 1.5 & Lifelong \\
\hline
\end{tabular}


sought from NFl specialists or soft tissue tumour/peripheral nerve surgeons as removal occasionally results in neurological deficit.

Plexiform neurofibromas cause significant morbidity because they are diffuse, grow along the length of a nerve and may involve multiple nerve branches and plexi. ${ }^{26}$ The lesions can be nodular, and multiple discrete tumours may develop on nerve trunks. Plexiform neurofibromas infiltrate surrounding soft tissue and bony hypertrophy is evident in some instances. ${ }^{26} \mathrm{~A}$ large area of pigmentation often betrays the presence of a deep seated neurofibroma. The growth rate is unpredictable and there may be periods of rapid growth, particularly in adolescence, followed by periods of relative inactivity. Facial plexiform neurofibromas causing disfigurement appear during the first three years of life if they are to develop at all. ${ }^{12}$ Removal of benign plexiform neurofibromas is frequently very difficult due to encroachment of the tumour on surrounding structures and nerves and its inherent vascular nature. Life threatening haemorrhage can occur, particularly with facial plexiform neurofibromas. Expert advice from experienced soft tissue tumour or plastic surgeons is essential before removal. A number of agents (including farnesyl transferase inhibitors, antiangiogenesis drugs and fibroblast inhibitors) are being used in clinical trials to assess their therapeutic effect on growth of plexiform neurofibromas. ${ }^{27}$ Currently, there is insufficient evidence to support the use of any of these drugs in patients with symptomatic plexiform neurofibromas, and radiotherapy is contraindicated in benign tumours because of the risk of malignancy.

\section{Malignant peripheral nerve sheath tumours}

There is an $8-13 \%$ lifetime risk of developing MPNST in NF1, predominantly in individuals aged $20-35$ years. ${ }^{28}$ These cancers are hard to detect, metastasise widely and often augur a poor prognosis. ${ }^{29}$ MPNST usually, but not invariably, arise in preexisting plexiform neurofibromas. NFl patients should seek an urgent expert opinion from specialist neurofibromatosis clinics or soft tissue tumour units if they develop any of the following in association with a subcutaneous or plexiform neurofibroma: persistent pain lasting for longer than a month or pain that disturbs sleep; new or unexplained neurological deficit or sphincter disturbance; alteration in the texture of a neurofibroma from soft to hard; and rapid increase in the size of a neurofibroma. ${ }^{29}$ Clinicians should be aware that occasionally symptoms arise from a plexiform neurofibroma that is not visible or palpable.

Individuals who have been treated with radiotherapy, have a personal or family history of cancer, optic pathway glioma, whole gene deletion, multiple subcutaneous neurofibromas or neurofibromatous neuropathy might have an increased risk of developing MPNST and require careful clinical monitoring. ${ }^{29-33}$

${ }^{18}$ Fluorodeoxyglucose positron emission tomography allows the visualisation and quantification of glucose metabolism in cells and is a useful diagnostic tool in differentiating benign plexiform neurofibromas from MPNST. ${ }^{34}$ The aim of treatment is complete removal of the lesion with tumour free margins. ${ }^{29}$ Adjuvant radiotherapy has a role in treating MPNST larger than $5 \mathrm{~cm}$, high grade lesions and incompletely excised tumours. ${ }^{29}$ Ifosfamide and doxorubicin are administered as palliative therapy in patients with metastatic disease and to reduce the size of a tumour with the aim of making it amenable to surgery. ${ }^{29}$

\section{Glomus tumours}

An association has been reported recently between glomus tumours and NF1. ${ }^{35}$ Glomus bodies are small, dermal, encapsulated arteriovenous anastomoses, commonest in the fingertips where they regulate peripheral blood flow and hence body temperature. The glomus tumour is usually solitary but multiple lesions have been observed in NFl individuals. ${ }^{35}$ The lesion is located most frequently under the fingernail and presents with pain, cold sensitivity and excruciating very localised tenderness. The symptoms should be differentiated from those caused by subcutaneous neurofibromas and the treatment is local excision of the tumour.

\section{Neurological problems}

Neurological examination should be undertaken during annual assessment. Any unexplained neurological signs and symptoms merit referral to a neurologist. Urgent advice is mandatory if individuals experience acute or progressive sensory disturbance, motor deficit and incoordination or sphincter disturbance which could be indicative of an intracranial lesion or spinal cord compression. Headaches on waking, morning vomiting and altered consciousness are suggestive of raised intracranial pressure and constitute a neurological emergency.

Neurological complications develop from tumours and malformations, including aqueduct stenosis. ${ }^{12} 36$ Skull deformity due to sphenoid wing dysplasia leads to pulsating exophthalmos as the temporal lobe herniates into the orbit. ${ }^{12}$ Severe scoliosis deforms the spine and results in cord compression and respiratory compromise. ${ }^{12}$ Neurological sequelae are the consequence of pressure on peripheral and spinal nerves and the spinal cord. Epilepsy is usually mild, occurs in approximately $6-7 \%$ of NFl individuals and is likely to be related to an underlying cortical dysgenesis. ${ }^{37}$ Cerebrovascular disease, including carotid artery stenosis/occlusion, haemorrhage and aneurysm is part of the spectrum of NFl vasculopathy. ${ }^{38}$ The causes of cognitive impairment, neurofibromatous neuropathy and multiple sclerosis in NFl remain unclear. ${ }^{33} 3940$

\section{Cognitive problems and behavioural difficulties}

Cognitive problems are the commonest neurological complication in NFI individuals and usually present as an IQ in the low average range; severe intellectual deficit with an IQ $<70$ is rare. $^{39}{ }^{41} 42$ Specific learning problems have been observed in 30 $60 \%$ of NFl children. ${ }^{39}{ }^{41-43}$ A child with a specific learning difficulty will fail to achieve his or her full academic potential, regardless of cultural or socioeconomic background, and in the absence of overt neurological, genetic or general medical problems. The disorder may be evident despite a normal or, more rarely, above average intelligence and includes clumsiness, reading/writing difficulties, visual spatial problems, working memory impairment and attention deficits. Behavioural problems comprise sleep disturbance, impaired socialisation, low self esteem and poor interpretation of social cues. There is an increased frequency of attention deficit hyperactivity and of autistic spectrum disorders. ${ }^{44}{ }^{45}$

Ideally a detailed developmental assessment should be performed as soon as possible and definitely before school. Progress at school should be ascertained as part of the yearly assessment with enquiries about the child's sleep patterns, ability to focus on an activity, distractibility, social interaction and fine and gross motor skills. NFl children frequently have difficulty in dressing, holding a pencil, hopping, running and riding a bike compared with non-affected peers. Ligament laxity can contribute to delay in acquiring fine and gross motor skills. A special educational needs coordinator needs to be involved at an early stage and an educational statement should be prepared if appropriate. Close liaison between teachers, educational psychologists, occupational therapists and community paediatricians ensures that the child receives the optimum assessment and remedial support. Children with attention deficit frequently respond well to methylphenidate under experienced supervision, and cognitive behavioural therapy can be helpful. ${ }^{4145}$ The benefit of the systematic use of 
methylphenidate in NF1 adults with attention deficit disorder has not been investigated.

The underlying pathogenesis of cognitive impairment in NFl has not been determined and there is no consensus concerning the causative role of $\mathrm{T} 2$ hyperintensities in the brain..$^{41}{ }^{45} \mathrm{~A}$ recent study on a mouse model for NFl has shown that attention deficits and visual spatial impairment are reversed by lovostatin, which is a specific inhibitor of HMG-CoA, the rate limiting enzyme in cholesterol biosynthesis. ${ }^{46}$ Current clinical studies are investigating the safety profile and tolerability of statin drugs in children with NFl. At present there is no justification for the use of these drugs in the treatment of cognitive impairment in NFl individuals.

Although clumsiness improves with age, overall cognitive impairment remains stable in adulthood. Adults should be asked about their literacy and numeracy as impairment of these skills reduces clinic attendance and understanding of information about their condition. Referral to adult literacy classes might be appropriate in some instances. Clinic visits should be followed where possible by a telephone call to ascertain that the individual understands his/her care plan.

\section{Central nervous system tumours}

Glioma is the predominant tumour type in NFl and occurs in all parts of the nervous system, with a predilection for the optic pathways, brainstem and cerebellum. ${ }^{36}$ Brainstem gliomas manifest as diffuse or focal tumours and frequently have a more indolent course in NFl than in the general population although occasionally they can behave aggressively. ${ }^{36} 47$ Symptomatic and progressive tumours are higher grade astrocytomas than pilocytic astrocytomas which have a more benign outcome. ${ }^{36}{ }^{47}$ A recent study indicated that symptomatic tumours, those with adult onset and gliomas situated outside the optic pathway are associated with reduced survival. Meningiomas and vestibular schwannomas are the hallmark of NF2 and do not occur with increased frequency in NF1.

\section{Optic pathway gliomas}

Optic pathway gliomas (OPG) are grade 1, pilocytic astrocytomas and occur in about $15 \%$ of children with NF1. ${ }^{48}$ They are often asymptomatic and more indolent than their counterparts in the general population. However, some tumours produce impaired visual acuity, abnormal colour vision, visual field loss, squint, pupillary abnormalities, pale optic disc, proptosis and hypothalamic dysfunction. The risk of symptomatic OPG is greatest in children under 7 years, and older individuals rarely develop tumours that require medical intervention. ${ }^{48} 49$

Young children do not complain of visual impairment until it is advanced and sometimes only when they have bilateral visual loss. Parents need to be alert to possible pointers of visual problems: failure to pick up small toys and bumping into objects. Visual assessment is often problematic in young children and those with cognitive deficits. Recognition of visual acuity can be assessed at a developmental age of 3 years, colour vision at 5 years and visual fields at age 8 years. In the UK we have not yet detected an asymptomatic child on screening who later required treatment. None the less, the greatest risk of developing OPG is in young children, and those under 7 years should have annual visual acuity and fundoscopy looking for optic disc pallor and elevation. One baseline assessment of colour vision and visual fields should be undertaken when the child is mature enough to cope with the test. Brain MRI screening for OPG is not indicated as treatment is not required in the absence of progressive visual disturbance or proptosis. Diffusion tensor imaging has proved useful for detecting OPG in a mouse model and might be a valuable screening tool in children in the future. ${ }^{50}$
Specialist advice is essential for the management of OPG and therapy is usually with vincristine and cisplatinum. ${ }^{51}$ Occasionally surgery is warranted to deal with severe proptosis or to debulk extensive chiasmal gliomas. Radiotherapy is not advocated in young children because of potential second malignancy, neuropsychological, vascular and endocrine consequences. Rapamycin reduces astrocyte growth in vitro and might have a future therapeutic role in the management of OPG. ${ }^{52}$

Neurofibromas cause neurological symptoms through pressure on peripheral nerves, spinal nerve roots and on the spinal cord. Neurofibromas in the high cervical region appear to have a high risk of causing cord compression although the reason is not clear. None the less, many individuals with radiological cord compression have no neurological deficit and do not always require surgery. Hence referral to a tertiary centre is advocated for specialist advice.

\section{Orthopaedic problems}

Approximately $2 \%$ of individuals with NFl develop bowing of the long bones, particularly the tibia and/or pseudarthrosis (a false joint in a long bone). ${ }^{12}$ The disorder is caused by an intrinsic defect of bone formation and bowing is apparent in the first few months of life. Fracture often occurs spontaneously or after trivial injury and there is delayed healing. Surgery is usually necessary and amputation of the affected limb is required in some cases. Infants should be examined for the presence of bowing of the long bone and clinicians should consider the possibility of pseudarthrosis when assessing young children for possible non-accidental injury.

NFl children need yearly assessment of the spine, and individuals with clinical evidence of scoliosis should be referred for expert orthopaedic advice and imaging. NFl causes disruption of bone maintenance and reduced bone mineral density. ${ }^{53}$ Scoliosis most commonly involves the lower cervical and upper thoracic spine and is either idiopathic or dystrophic. ${ }^{12}{ }^{54}$ Dystrophic curves are associated with additional kyphosis and onset is earlier than in idiopathic cases. Dystrophic scoliosis typically involves 4-6 segments, causes distortion of the vertebral bodies and ribs and is rapidly progressive, requiring early spinal fusion. It can be associated with underlying plexiform neurofibroma and in severe cases results in respiratory compromise. Disturbed sleep and excessive snoring can indicate impaired respiratory function and people with severe scoliosis require regular pulmonary function tests. Surgeons conversant with NFl should perform spinal surgery, as intrinsic abnormalities of bone make instrumentation difficult in this group. Clinicians need to be vigilant about the possibility of osteoporosis and have a low threshold for performing dexa scans.

Non-ossifying fibromas have been observed in association with NF1 and are benign lesions of the tubular long bones. ${ }^{55}$ Occasionally they cause pain and pathological fracture and need to be distinguished from malignant bone tumours.

\section{Cardiovascular problems}

Congenital heart disease, especially pulmonary stenosis, and hypertension are observed in NF $1 .^{38}$ A careful examination of the heart should be undertaken and if an unexplained murmur is present the child should be referred for a cardiology opinion and echocardiograph. Blood pressure must be checked annually and should be less than 140/90 $\mathrm{mm} \mathrm{Hg}$ and less than 130/ $85 \mathrm{~mm} \mathrm{Hg}$ in individuals with end organ damage or diabetes mellitus. If the blood pressure is found to be high during a clinic visit it should be checked three times in one month to verify the findings. Some adults are happy to monitor their own blood pressure using portable machines at home. Coarctation of 
the aorta can be detected by checking the blood pressure in the upper and lower limbs.

Renal artery stenosis occurs in approximately $2 \%$ of the NFl population and the diagnosis should be considered in hypertensive children, young adults and pregnant women, refractory hypertension in older individuals and those with an abdominal bruit. ${ }^{12}{ }^{38}$ Renal artery stenosis may be bilateral and is produced by stenosis of small or large vessels, aneurysm formation or extrinsic compression by an adjacent tumour. Individuals require evaluation at a specialist centre and treatment includes antihypertensives, percutaneous transluminal angioplasty and surgery. The outcome is variable as a result of recurrent stenosis following surgery. ${ }^{56}$

Phaeochromocytoma occurs in approximately $2 \%$ of NFl individuals and about $12 \%$ of tumours are malignant. ${ }^{57}$ Clinical presentation includes hypertension/paroxysmal hypertension, palpitations, headache, dizziness or sweating. The 24 hour urinary catecholamines should be checked and if there are associated symptoms, it is advisable to commence the urine collection when the patient is symptomatic. Where there is a high index of suspicion, referral to specialist centres for evaluation and management is recommended. Treatment involves alpha and beta blockade before surgery and duodenal carcinoid may coexist with phaeochromocytoma. ${ }^{12}$ Treatment of essential hypertension is the same as in the general population.

\section{Gastrointestinal problems}

Abdominal bloating, pain, dyspepsia, haemorrhage and constipation may denote a gastrointestinal neurofibroma. Carcinoid tumours have a predilection for the duodenum where they give rise to facial flushing, diarrhoea, right sided cardiac lesions, facial telangiectasiae and bronchoconstriction. ${ }^{58}$ Increased urinary levels of the serotonin metabolite 5-hydroxyindoleacetic acid confirm the diagnosis. Gastrointestinal stromal tumours, the commonest mesenchymal tumours of the gastrointestinal tract, have been observed recently in association with NFl. ${ }^{59}$ Patients present with anaemia and gastrointestinal bleeding but the majority of NFl related tumours have a good prognosis.

\section{Psychological problems}

Psychological problems stem from disfigurement caused by neurofibromas and from the complex and unpredictable nature of the disease. Symptoms of anxiety and depression are common and there are reported instances of attempted suicide, psychosis and sociopathic behaviour. ${ }^{39}{ }^{60}$ Anxiety and depression usually respond to a combination of antidepressants and counselling. NFl specialist advisors, psychiatrists and counsellors all play a role in managing psychological complications.

\section{Contraception and pregnancy}

Recent research has shown that $75 \%$ of neurofibromas carry progesterone receptors. ${ }^{61}$ However, there has been no confirmation that the combined oral contraceptive pill or the progesterone only pill contributes to neurofibroma growth. ${ }^{62}$ One study has reported an increased risk of perinatal complications in NF1, with a higher stillbirth rate, intrauterine growth retardation and caesarean section rate. ${ }^{63}$ Hence close liaison between the obstetrician and neurofibromatosis clinician is important when caring for pregnant individuals with NFl. During pregnancy, neurofibromas may grow in size and number and clinicians need to be aware of the risk of cord compression if spinal plexiform neurofibromas expand. ${ }^{64}$ Obstetricians should ensure pelvic neurofibromas do not impede delivery of the baby. Hypertension requires careful evaluation (see section on cardiovascular disease). Monitoring of anticonvulsant medication is essential and patients should be informed of the potential teratogenic effects of antiepileptic drugs and given advice on breastfeeding. Patients on anticonvulsants need folic acid $5 \mathrm{mg}$ daily before conception, where possible, and vitamin $\mathrm{K}$ is administered to the mother for one month before delivery and to the infant at birth.

The child requires assessment at birth for possible early complications of NFl and at least yearly review until the disease status is clarified. If there are no features by the age of 2 years, NFl is unlikely but one final review at 5 years is advised.

\section{GENETIC COUNSELLING}

An individual with NFl has a $50 \%$ risk of passing on the condition to an offspring but the clinical problems cannot be predicted, even within families. ${ }^{18}$ When the complications that cause lifelong morbidity or early mortality are considered, the risk of having a severely affected child is about 1 in 12 .

It is imperative to examine the parents for cutaneous stigmata or for Lisch nodules in the $50 \%$ of individuals who are the first in the family to be affected. Occasionally, a parent will be found to have a segmental/mosaic form of NFl. Although the parent might have few health problems he or she would have an increased risk of having a child with classical NFl. In the absence of clinical signs of NFl, the risk to the parent of having another child with NFI is extremely small and less than $1 \%$.

The NFI gene mutation is found in approximately $85-95 \%$ of cases using a combination of molecular techniques, including dHPLC, direct sequencing, FISH, MLPA and array CGH. ${ }^{65}{ }^{66}$ All Wales Medical Genetic Services at the Institute of Medical Genetics in Cardiff offers a clinical mutation testing service that takes approximately 8 weeks to produce a result. Mutational analysis of the entire NFI coding region and flanking splice sites has been performed on 169 individuals in the past 2 years. Prenatal testing is possible by direct mutation testing of fetal DNA extracted from chorionic villous sampling or from amniocentesis. Alternatively, DNA markers in families with two or more affected individuals can be used for this purpose. However, many do not take up the option of prenatal assessment because of the inability to determine disease severity. Preimplantation genetic diagnosis is also available and gives a further option for couples wishing to avoid therapeutic termination of pregnancy. ${ }^{67}$ The diagnosis is ascertained using single cells removed from 3 day old embryos, and those that do not carry the NF1 mutation are transferred to the mother. Genetic counselling prior to conception is advised in all NF1 individuals.

\section{SPECIALIST NF 1 CLINICS}

It is recommended that multidisciplinary neurofibromatosis clinics include a lead clinician, named consultants who are experts in their field and a specialist nurse. Ideally, the disciplines of neurology, paediatrics, genetics, ophthalmology, neurosurgery, plastic surgery, orthopaedics, soft tissue tumour surgery, psychiatry, dermatology, radiology and pathology should be represented. The role of the specialist clinic is to diagnose NFl in difficult cases, monitor and manage complex disease, and educate and support the patient and family. The specialist service also provides a forum for clinical audit and academic interaction through multidisciplinary meetings and video conferencing.

\section{CONCLUSIONS}

Close collaboration between NFl clinicians will facilitate a uniform approach to the diagnosis and management of NFI and its complications. Reliable clinical and radiological assessment will be helpful in determining the value of potential therapeutic agents. Furthermore, the formation of a standar- 
dised UK database will facilitate the evaluation of care and long term response to treatment for this complex neurocutaneous disease.

\section{ACKNOWLEDGEMENTS}

We are grateful to the following for their advice and support: Robert Listernick, Linda Partridge, and The UK Neurofibromatosis Association.

\section{Authors' affiliations}

R E Ferner, Department of Neurology, Guy's and St Thomas' Hospitals, London, UK

S M Huson, D G Evans, Department of Medical Genetics, St Mary's Hospital, Manchester, UK

N Thomas, Department of Neurosurgery, Kings College Hospital, London, UK

C Moss, Department of Dermatology, Birmingham Children's Hospital, UK H Willshaw, Department of Ophthalmology, Birmingham Children's Hospital, UK

M Upadhyaya, Institute of Medical Genetics, University of Wales College of Medicine, Cardiff, UK

R Towers, Royal Marsden Hospital London, UK

M Gleeson, Department of ENT, Guy's Hospital London, UK

C Steiger, Department of Community Paediatrics, Alder Hey Children's

Hospital, Liverpool, UK

A Kirby, Dyscovery Centre, University of Wales, Newport, UK

Competing interests: None.

Contact addresses: The Neurofibromatosis Association, 38 High St, Kingston on Thames KT1 1HL, UK; Tel 0208439 1234, Fax 0208439 1200; registered charity number 1078790. The Neurofibromatosis specialist advisors are based around the UK and can be contacted via the Neurofibromatosis Association.

For information on Genetic Units see: http://www.gig.org.uk/services.html

Neurofibromatosis specialist centres: Dr Rosalie Ferner, Department of Neurology, Guy's Hospital, St Thomas St, London SEl 9RT, UK, Tel 020 71883970 (Guy's and St Thomas' specialist neurofibromatosis nurse: Melissa Vann-Blockley, Tel 0207 188-3971); Professor Gareth Evans and Dr Susan Huson, University Department of Medical Genetics and Regional Genetics Service, St Mary's Hospital, Hathersage Rd, Manchester M13 OJH, UK, Tel 01612766264.

\section{REFERENCES}

1 Zanca A, Zanca A. Antique illustrations of neurofibromatosis. Int J Dermatol 1980;19:55-8.

2 von Recklinghausen FD. Über die Multiplen Fibrome der Haut und Ihre Beziehung zu den Multiplen Neuromen. Berlin: Hirschwald A, 1882.

3 National Institutes of Health Consensus Development Conference Statement: Neurofibromatosis. Arch Neurol Chicago 1988;45:575-8.

4 Viskochil D, Buchberg AN, Xu G, Cawthon RM, Stevens J, Wolff RK, Culver M, Carey JC, Copeland NG, Jenkins NA, White R, O'Connell P. Deletions and a translocation interrupt a cloned gene at the neurofibromatosis type 1 locus. Cell 1990;62:1887-92.

5 Wallace MR, Marchuk DA, Anderson LB, Letcher R, Odeh HM, Saulino AM, Fountain JW, Bereton A, Nicholson J, Mitchell AL, Brownstein BH, Collins FS. Type 1 neurofibromatosis gene; identification of a larger transcript disrupted in three NF1 patients. Science 1990;24:181-6.

6 Xu GF, O'Connell P, Viskochil D, Cawthon R, Robertson M, Culver M, Dunn D, Stevens J, Gesteland R, White R, Weiss R. The neurofibromatosis type 1 gene encodes a protein related to GAP. Cell 1990;62:599-608.

7 Gutmann DH, Wood DL, Collins FS. Identification of the neurofibromatosis 1 gene product. Proc Natl Acad Sci USA 1991;88:9658-72.

8 Daston MM, Scrable H, Nordlund M, Sturbaum AK, Nissen LM, Ratner N. The protein product of the neurofibromatosis type 1 gene is expressed at highest abundance in neurons, Schwann cells and oligodendrocytes. Neuron 1992;8:415-28.

9 Huson SM, Compston DAS, Clark P, Harper PS. A genetic study of von Recklinghausen neurofibromatosis in south east Wales. 1. Prevalence, fitness, mutation rate, and effect of parental transmission on severity. J Med Genet 1989;26:704-11

10 Ruggierei M, Huson SM. The clinical and diagnostic implications of mosaicism in the neurofibromatoses. Neurology 2001;56:1433-43.

11 Huson SM, Harper PS, Compston DAS. Von Recklinghausen neurofibromatosis: clinical and population study in south east Wales. Brain 1988;111:55-81.

12 Korf BR. Diagnostic outcome in children with multiple café au lait spots. Pediatrics 1992:90:924-7.
13 DiPaolo DP, Zimmerman RA, Rorke LB, Zackai EH, Bilaniuk LT, Yachnis AT Neurofibromatosis type 1: pathologic substrate of high-signal-intensity foci in the brain. Radiology 1995; 195:721-4.

14 Bognanno JR, Edwards MK, Lee TA, Dunn DW, Roos KL, Klatte EC. Cranial imaging in neurofibromatosis. Am J Radiol 1988;151:381-8.

15 Ferner RE, Chaudhuri R, Bingham J, Cox T, Hughes RAC. The nature and evolution of increased intensity T2 weighted lesions and their relationship to intellectual impairment. J Neurol Neurosurg Psychiatry 1993;56:492-5.

16 North K, Joy P, Yuille D, Cocks N, Mobbs E, Hutchins P, McHugh K, deSilva M. Specific learning disability in children with neurofibromatosis type 1: significance of MRI abnormalities. Neurology 1997;44:878-83.

17 DeBella K, Poskitt K, Szudek J, Friedman JM. Use of "unidentified bright objects" on brain MRI for diagnosis of neurofibromatosis 1 in children. Neurology 2000:55:1067-8

18 Korf BR, Huson SM. The Phakamatoses. In: Rimoin D, Connor JM, Pyeritz RE Korf BR, eds. Principles and practice of medical genetics, 5th edn. Edinburgh: Churchill Livingstone, 2006: 2817-50.

19 Bandipalliam P. Syndrome of early onset colon cancer, haematological malignancy and features of neurofibromatosis in HNPCC families with homozygous mismatch repair gene mutations. Fam Cancer 2005;4:323-33.

20 De Luca A, Bottiloo I, Sarkozy A, Carta C, Neri C, Bellacchio E, Schirinzi A, Conti E, Zampino G, Battaglia A, Majore S, Rinaldi MM, Carella M, Marino B, Pizzuti A, Digilio MC, Tartaglia M, Dallapiccola B. NF1 gene mutations represent the major molecular event underlying neurofibromatosis-Noonan syndrome. Am J Med Genet 2005;77:1092-1101.

21 Evans DGR, Moran A, King A, Saeed S, Gurusinghe N, Ramsden R. Incidence of vestibular schwannoma and neurofibromatosis 2 in the north west of England over a 10-year period: higher incidence than previously thought. Otol Neurotol 2005;26:93-7.

22 Trofatter J, MacCollin M, Rutter JL, Murrell JR, Duyao MP, Parry DM, Eldridge R, Kley N, Menn AG, Pulaski K, Haase VH, Ambrose CM, Munroe D, Bove C, Haines JL, Martuza RL, MacDonald ME, Seizinger BR, Short MP, Buckler AJ, Gusella JF. A novel moesin-esrin-radixin-like gene is a candidate for the neurofibromatosis 2 tumours suppressor. Cell 1993;72:791-800.

23 Evans DGR, Huson SM, Donnai D, Neary W, Blair V, Newton V, Harris R. A clinical study of type 2 neurofibromatosis. Q J Med 1992;84:603-18.

24 MacCollin M, Chiocca EA, Evans DG, Friedman JM, Horvitz R, Jaramillo D, Lev M, Mautner VF, Nimura M, Plotkin SR, Sang CN, Stemmer-Rachamimov A, Roach ES. Diagnostic criteria for schwannomatosis. Neurology 2005;64:1838-45

25 Cambiaghi S, Restano L, Caputo R. Juvenile xanthogranuloma associated with neurofibromatosis 1: 14 patients without evidence of haematologic malignancies. Paediatr Dermatol 2004;21:97-101.

26 Korf BR. Plexiform neurofibromas. Am J Med Genet 199, 89:31-7.

27 Packer RJ, Gutmann DH, Rubenstein A, Viskochil D, Zimmerman RA, Verzina G, Small J, Korf B. Plexiform neurofibromas in NF1: toward biologic-based therapy. Neurology 2002;58:1461-70.

28 Evans DG, Baser ME, McGaughran J, Sharif S, Howard E, Moran A. Malignan peripheral nerve sheath tumours in neurofibromatosis 1. J Med Genet 2002;39:311-14.

29 Ferner RE, Gutmann DH. International consensus statement on malignant peripheral nerve sheath tumours in neurofibromatosis 1. Cancer Res 2002;62:1573-7.

30 Sharif S, Ferner R, Birch JM, Gillespie JE, Gattamaneni HR, Baser ME, Evans DG Second primary tumours in neurofibromatosis 1 patients treated for optic glioma: substantial risks after radiotherapy. J Clin Oncol 2006;24:2570-5.

31 De Raedt T, Brems H, Wolkenstein P, Vidaud D, Pilotti S, Perrone F, Mautner V, Frahm S, Sciot R, Legius E. Elevated risk for MPNST in NF1 microdeletion patients. Am J Hum Genet 2003;72:1288-92.

32 Khosrotehrani K, Bastuji-Garin S, Riccardi VM, Birch P, Friedman JM, Wolkenstein P. Subcutaneous neurofibromas are associated with mortality in neurofibromatosis 1: a cohort of 703 patients. Am J Med Genet 2005; 132:49-53

33 Ferner RE, Hall SM, Hughes RAC, Upadhyaya M, Johnson MR. Neurofibromatous neuropathy in neurofibromatosis 1. J Med Genet 2004;41:837-41.

34 Ferner R, Lucas JD, O'Doherty M, Hughes RA, Smith MA, Cronin BF, Bingham J. Evaluation of 18 -fluorodeoxyglucose positron emission tomography ( ${ }^{18} \mathrm{FDG}$ PET) in the detection of malignant peripheral nerve sheath tumours arising from within plexiform neurofibromas in neurofibromatosis 1. J Neurol Neurosurg Psychiatry 2000;68:353-7.

35 De Smet L, Sciot R, Legius E. Multifocal glomus tumours of the fingers in two patients with neurofibromatosis type 1. J Med Genet 2002;39:e45.

36 Créange A, Zeller J, Rostaing-Rigattieri S, Brugieres P, Degos JD, Revuz J, Wolkenstein P. Neurological complications of neurofibromatosis type 1 in adulthood. Brain 1999;122:473-81.

37 Vivarelli R, Grosso S, Calabrese F, Farnetani M, Di Bartolo R, Morgese G Balestri P. Epilepsy in neurofibromatosis 1. J Child Neurol, 18:338-42.

38 Friedman JM, Arbiser J, Epstein JA, Gutmann DH, Huot SJ, Lin AE, McManus B, Korf BR. Cardiovascular disease in neurofibromatosis 1: a report of the NF1 Cardiovascular Task Force. Genet Med 2003;4:105-11.

39 Ferner RE, Hughes RAC, Weinman J. Intellectual impairment in neurofibromatosis. J Neurol Sci 1996;138:125-33.

40 Ferner RE, Hughes RAC, Johnson MR. Neurofibromatosis 1 and multiple sclerosis. J Neurol Neurosurg Psychiatry 1995;56:492-5.

41 North KN, Riccardi VM, Samango-Sprouse C, Ferner R, Moore B, Legius E, Ratner N, Denckla MB. Cognitive function and academic performance in neurofibromatosis 1: consensus statement from the NF1 Cognitive Disorders Task Force. Neurology 1997;48:1121-7. 
42 Ozonoff S. Cognitive impairment in neurofibromatosis 1. Am J Med Genet 1999;89:45-52.

43 Hyman SL, Shores A, North KN. The nature and frequency of cognitive deficits in children with neurofibromatosis type 1. Neurology 2005;11:1037-44.

44 Johnson H, Wiggs L, Stores G, Huson SM. Psychological disturbance and sleep disorders in children with neurofibromatosis type 1. Dev Med Child Neurol 2005;47:237-42

45 Mautner VF, Kluwe L, Thakker SD, Leark RA. Treatment of ADHD in neurofibromatosis 1. Dev Med Child Neurol 2002;44:164-70.

46 Li W, Cui Y, Kushner SA, Brown RA, Jentsch JD, Franklin PW, Cannon TD, Silva AJ. The HMG-CoA reductase inhibitor lovostatin reverses the learning and attention deficits in a mouse model of neurofibromatosis 1. Curr Biol 2005; 15:1961-7

47 Pollack IF, Mulvihill JJ. Special issues in the management of gliomas in children with neurofibromatosis 1. J Neurooncol 1996;28:257-68.

48 Listernick R, Louis DN, Packer RJ, Gutmann DH. Optic pathway gliomas in children with neurofibromatosis type 1: consensus statement from the NF1 optic pathway glioma study. Ann Neurol 1997:41:1433-9.

49 Listernick R, Ferner RE, Piersall L, Sharif S, Gutmann DH, Charrow J. Late-onset optic pathway tumours in children with neurofibromatosis 1. Neurology 2004;63:1944-6.

50 Bajenaru ML, Garbow JR, Perry A, Hernandez MR, Gutmann DH. Natural history of neurofibromatosis 1-associated optic nerve glioma in mice. Ann Neurol 2005:57: 119-27.

51 Packer RJ, Alter J, Allen J, Phillips P, Geyer R, Nicholson HS, Jakacki R, Kurczynski E, Needle M, Finlay J, Reaman G, Boyett JM. Carboplatin and vincristine chemotherapy for children with newly diagnosed progressive lowgrade gliomas. J Neurosurg 1997;86:747-54.

52 Dasgupta B, Yi Y, Chen DY, Weber JD, Gutmann DH. Proteomic analysis reveals hyper-activation of the mammalian target of rapamycin pathway in neurofibromatosis 1-associated human and mouse brain tumours. Cancer Res $2005 ; 1: 2755-60$

53 Lammert M, Kappler M, Mautner VF, Lammert K, Storkel S, Friedman JM, Atkins D. Decreased bone mineral density in patients with neurofibromatosis 1. Osteoporos Int 2005;16:1161-6.

54 Crawford AH Jr, Bagamery N. Osseous manifestations of neurofibromatosis in childhood. J Pediatr Orthop 1986;6:72-88.
55 Howlett DC, Farrugia MM, Ferner RE, Rankin SC. Multiple lower limb nonossifying fibromas in siblings with neurofibromatosis. Eur J Radiol 1998;26:3.

56 Booth C, Preston R, Clark G, Reidy J. Management of renal vascular disease in neurofibromatosis type 1 and the role of percutaneous transluminal angioplasty. Nephrol Dial Transplant 2002;17:1235-40.

57 Bausch B, Borozdin W, Neumann H, European-American Phaeochromocytoma Study Group. Clinical and genetic characteristics of patients with neurofibromatosis type 1 and phaeochromocytoma. N Engl J Med 2006:354:2729-31.

58 Hough DR, Chan A, Davidson H. Von Recklinghausen's disease associated with gastrointestinal carcinoid tumours. Cancer 1983;51:2206-8.

59 Miettinen M, Fetsch JF, Sobin LH, Lasota J. Gastrointestinal stromal tumours in patients with neurofibromatosis 1: a clinicopathologic and molecular genetic study of 45 cases. Am J Surg Pathol 2006;30:90-6.

60 Wolkenstein P, Zeller J, Revuz J, Ecosse E, Leplege A. Quality-of-life impairment in neurofibromatosis type 1: a cross-sectional study of 128 cases. Arch Dermato $2001 ; 137: 1421-5$

61 McLaughlin ME, Jacks T. Progesterone receptor expression in neurofibromas. Cancer Res 2003;63:752-5.

62 Lammert M, Mautner VF, Kluwe L. Do hormonal contraceptives stimulate growth of neurofibromas? A survey of 59 patients. BMC Cancer 2005:5:16.

63 Segal D, Holcberg G, Sapir O, Sheiner E, Mazor M, Katz M. Neurofibromatosis in pregnancy. Maternal and perinatal outcome. Eur J Obstet Gynecol Reprod Biol 1999:84:59-61.

64 Dugoff L, Sujansky E. Neurofibromatosis type 1 and pregnancy. Am J Med Genet 1996;66:7-10

65 Griffiths S, Thompson P, Frayling I, Upadhyaya M. Molecular diagnosis of neurofibromatosis type 1: 2 years experience. Fam Cancer, 2006;Aug 31 (Epub ahead of print)

66 Messiaen LM, Callens T, Mortier G, Beysen D, Vandenbroucke I, Van Roy N Speleman F, Paepe AD. Exhaustive mutation analysis of the NF1 gene allows identification of $95 \%$ of mutations and reveals a high frequency of unusual splicing defects. Hum Mutat 2000;15:541-5.

67 Verlinsky Y, Rechitsky S, Verlinsky O, Chistokhina A, Saharapova T, Masciangelo C, Levy M, Kaplan B, Lederer K, Kuliev A. Preimplantation diagnosis for neurofibromatosis. Reprod Biomed Online 2002;4:218-22.

\section{bmjupdates+}

bmjupdates+ is a unique and free alerting service, designed to keep you up to date with the medical literature that is truly important to your practice.

bmjupdates+ will alert you to important new research and will provide you with the best new evidence concerning important advances in health care, tailored to your medical interests and time demands.

Where does the information come from?

bmjupdates+ applies an expert critical appraisal filter to over 100 top medical journals A panel of over 2000 physicians find the few 'must read' studies for each area of clinical interest

Sign up to receive your tailored email alerts, searching access and more...

www.bmjupdates.com 